\title{
Involvement of amygdala pathways in the influence of post-training intra-amygdala norepinephrine and peripheral epinephrine on memory storage
}

\author{
K.C. Liang ${ }^{1}$, James L. McGaugh ${ }^{2}$ and H.-Y. Yao ${ }^{1}$ \\ 'Department of Psychology, National Taiwan University, Taipei (Taiwan) and ${ }^{2}$ Department of Psychobiology and Center for the Neurobiology \\ of Learning and Memory, University of California, Irvine, CA 92717 (U.S.A.)
}

(Accepted 5 July 1989)

Key words: Amygdala; Adrenaline; Inhibitory avoidance; Memory; Noradrenaline; Retention; Stria terminalis; Ventral amygdalofugal pathway

\begin{abstract}
These experiments examined the role of two major amygdala afferent-efferent pathways - the stria terminalis (ST) and the ventral amygdalofugal pathway (VAF) - in mediating the effects, on memory storage, of post-training intra-amygdala injections of norepinephrine (NE) and subcutaneous (s.c.) injections of epinephrine (E). Rats with either ST lesions or VAF transections and sham-operated rats were trained on a one-trial step-through inhibitory avoidance task and immediately after training received intra-amygdala injections of NE or a buffer solution. Other groups of VAF-transected animals received post-training s.c. injections of E or saline. ST lesions blocked the memory-enhancing effect of intra-amygdala injections of a low dose of NE $(0.2 \mu \mathrm{g})$ as well as the amnestic effect of a high dose of NE (5.0 $\mu \mathrm{g})$. In contrast, VAF transections did not block the memory-enhancing effect of NE $(0.2 \mu \mathrm{g})$. However, VAF transections attenuated the memory-enhancing effect of s.c. injections of $E$ : the effective dose of $E$ was shifted from 0.1 to $0.5 \mathrm{mg} / \mathrm{kg}$. These findings, considered together with previous evidence that ST lesions block the memory-enhancing effect of peripheral E injections, suggest that the VAF is involved in mediating the central influences of peripheral E on amygdala functioning, while the ST is involved in mediating amygdala influences on memory storage elsewhere in the brain.
\end{abstract}

\section{INTRODUCTION}

Extensive evidence suggests that the amygdala is involved in the modulation of memory storage processes. Lesions or electrical stimulation of the amygdala impair retention of a variety of recently learned responses (for review, see refs. 33, 34). In view of the findings that damage of the amygdala in rats or human patients results in retrograde amnesia which is temporally limited ${ }^{23,35}$, it seems unlikely that the amygdala is a site of permanent memory storage. Results from a number of studies suggest that amygdala influences on memory storage may involve its two major input-output pathways - the stria terminalis (ST) and the ventral amygdalofugal pathway $(\mathrm{VAF})^{3.13,16,17,20.21 .27 .28 .32}$. The findings that ST lesions significantly attenuate the amnestic effect of post-training electrical stimulation of the amygdala argue that the amygdala may be involved in modulating memory storage processing through its influences on neural processes in other brain regions ${ }^{20}$.

The amygdala receives noradrenergic projections from the locus coeruleus as well as other brainstem nuclei ${ }^{8,9,15}$.
There is extensive evidence indicating that treatments influencing noradrenergic activity in the amygdala influence memory formation: in an inhibitory avoidance task, post-trial intra-amygdala infusions of $\beta$-adrenergic antagonists impair retention ${ }^{10.26}$, and retention is enhanced by low doses of norepinephrine $(\mathrm{NE})^{19}$ and impaired by higher doses $^{6}$. In addition, naloxone, which enhances NE release by blocking opioid receptors, produces a propranolol-reversible memory enhancement when administered directly into the amygdala ${ }^{14}$. Intra-amygdala injections of NE have also been shown to affect taste aversion learning ${ }^{2}$. These findings suggest that the amygdala NE system may be involved in the endogenous modulation of memory storage.

It is well established that post-training systemic injections of epinephrine $(E)$, which does not readily enter the brain $^{31.38}$, improve retention in both appetitive and avoidance learning tasks ${ }^{11,25,36}$. Several recent findings from our laboratories indicate that the memory-enhancing effect of peripheral $\mathrm{E}$ involves the amygdala $\mathrm{NE}$ system: post-training intra-amygdala injections of propranolol attenuate the memory-enhancing effects of

Correspondence: K.C. Liang, Department of Psychology, National Taiwan University, Taipei, Taiwan 10764. R.O.C. 
peripherally administered $E$ and post-training intraamygdala injections of NE attenuate the learning deficit produced by adrenal demedullation ${ }^{19}$. We have also found that the memory-enhancing effect of peripherally administered $\mathrm{E}$ is attenuated in animals given intraamygdala injections of the NE neurotoxin DSP $-4^{18}$. Considered together, these findings suggest that peripheral $\mathrm{E}$ may activate $\mathrm{NE}$ projections from the brainstem to various brain regions, including the amygdala, and that NE released in the amygdala may, in turn, activate pathways which serve to modulate memory processing elsewhere in the brain. This view is consistent with the view that the locus coeruleus may play a critical role in integrating internal or external stimuli from the periphery to emotional or other behavior ${ }^{37}$ as well as the finding that $\mathrm{NE}$ released in the central amygdala nucleus is temporally correlated with plasma NE level in rats ${ }^{4}$.

According to our interpretation of these findings, severance of the afferents conveying the influences of peripheral $E$ to the amygdala should attenuate the memory-modulating effect of peripheral $E$ injections but should not block those produced by intra-amygdala NE injections. In contrast, severance of the pathway transmitting the memory modulatory influences from the amygdala to other brain regions should attenuate the effects of both peripherally administered $E$ and intraamygdally injected NE. We have previously shown that ST lesions attenuate the memory enhancing effect of peripherally administered $E^{21}$. To investigate these implications further, the present experiments examined the effects, on memory storage, of: (1) peripherally administered $\mathrm{E}$, in rats with VAF transections: and (2) intra-amygdally injected $\mathrm{NE}$, in rats with lesions of either the ST or VAF.

\section{MATERIALS AND METHODS}

Subjects

Male Sprague-Dawley rats, 50-60 days old, were obtained from the breeding center of National Yang-Ming Medical College (Expts. I and II) and Charles River Labs (Expt. III). They were individually housed upon arrival and maintained on a 12-h light-dark cycle (lights on at $07.00 \mathrm{~h}$ ) with food and water ad libitum.

\begin{abstract}
Surgery
Approximately 3 weeks after arrival, the rats were subjected to stereotaxic surgery under sodium pentobarbital anesthesia $(40$ $\mathrm{mg} / \mathrm{kg})$. Atropine sulfate $(0.3 \mathrm{mg} / \mathrm{kg})$ was given to prevent congestion. Rats in Expts. I and II received bilateral amygdala cannula implantation plus bilateral ST lesions or VAF transections or sham operations on either pathway. Rats in Expt. III received only VAF transections or sham operation.

ST lesions. To produce bilateral ST lesions, a Radionic TCZ electrode was placed into the brain with the tip at the fimbra-fornix level (AP $-1.0 \mathrm{~mm}$ from bregma, $\mathrm{ML} \pm 2.5 \mathrm{~mm}$, DV $-4.0 \mathrm{~mm}$ from dura ${ }^{30}$. Radio frequency currents $(2.5-3.0 \mathrm{~mA})$ generated by a DKI RFG-4A lesion maker were passed through the electrode for $30 \mathrm{~s}$. The electrode was then withdrawn from the brain and the burr hole was sealed with Gelfoam and bone wax. The sham operation followed the same procedure except that no current was delivered.

$V A F$ transection. The VAF transecting procedure was similar to that described previously ${ }^{20}$. A wire knife composed of a 30-gauge cannula containing a stainless-steel wire $(0.13 \mathrm{~mm}$ in diameter) was lowered into the brain (AP $0.0 \mathrm{~mm}, \mathrm{ML} \pm 2.5 \mathrm{~mm}, \mathrm{DV}-5.5 \mathrm{~mm}$ ). The wire was then forced out from the slightly curved opening of the cannula tip so that the wire-blade would protrude $2.0 \mathrm{~mm}$ from the tip in a position perpendicular to the cannula and suspend an angle
\end{abstract}

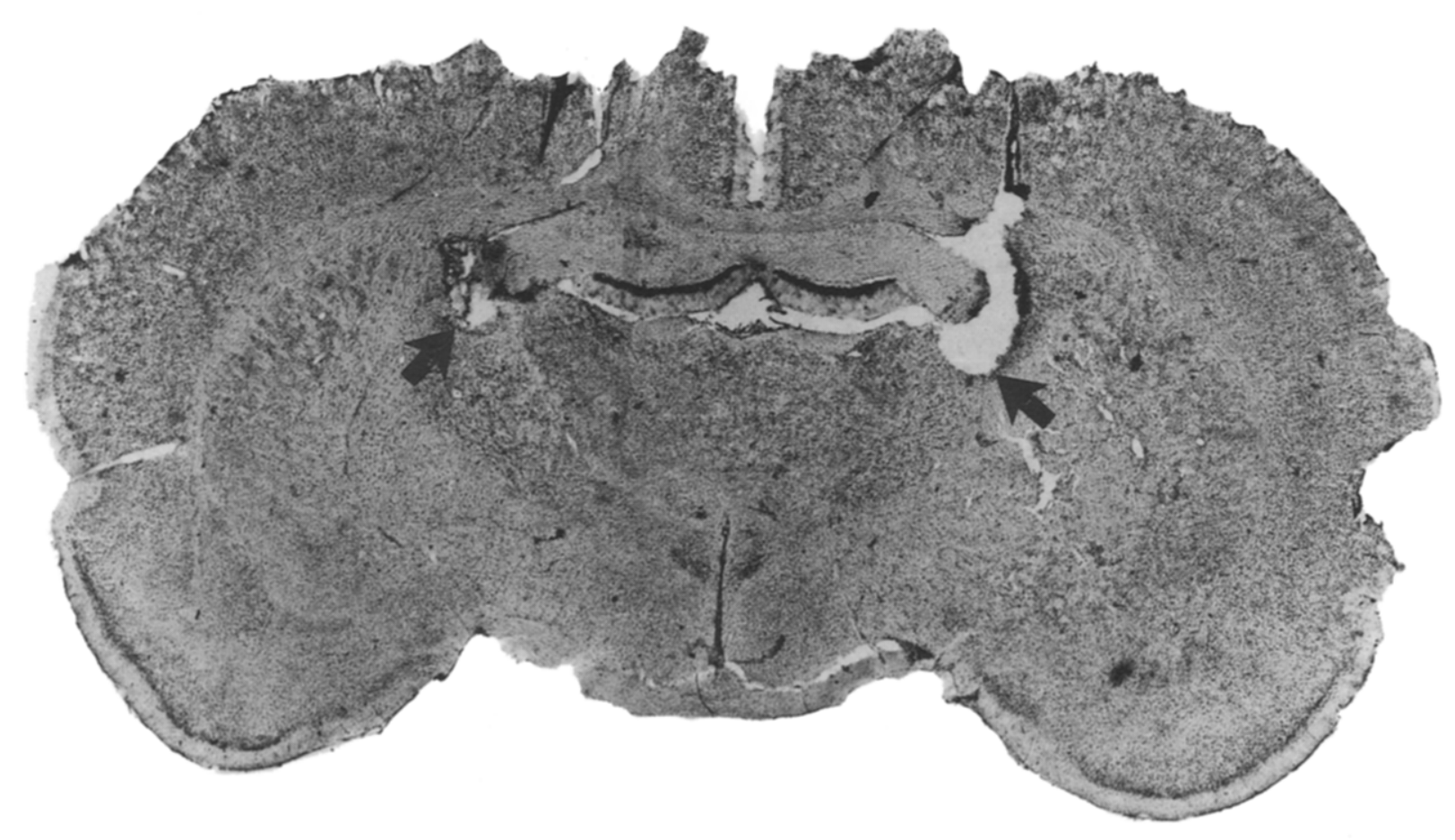

Fig. 1. Representative ST lesions. 
of $15^{\circ}$ laterally to the parasagittal plane of the cannula shaft. A cut was made between the lateral hypothalamus and the amygdala by moving the entire knife down and up once between $-5.5 \mathrm{~mm}$ and the floor of the brain. The knife was then retracted into the cannula and the cannula was withdrawn from the brain. Since simultaneous bilateral VAF transections are known to produce severe aphagia as well as adipsia resulting in high death rates, two unilateral transections were performed, with a 2-week interval between the surgeries. In the sham VAF operation, the cannula containing the knife was lowered to $-5.5 \mathrm{~mm}$ below the dura and then withdrawn (without extending the wire). The two unilateral sham operations were also separated by an interval of 2 weeks.

Amygdala cannula implantation. The amygdala cannula implantation surgery was performed following the ST or VAF surgery. Stainless-steel cannulae ( 23 gauge) were implanted bilaterally into the center of the amygdala (AP $-2.0 \mathrm{~mm}, \mathrm{ML} \pm 4.5 \mathrm{~mm}, \mathrm{DV}-6.0$ $\mathrm{mm}$ ). Two small stainless-steel screws were implanted over the right frontal and left posterior cortices serving as anchors. The entire complex was affixed on the skull with dental cement. A stylet was inserted into each cannula to maintain patency. For animals receiving VAF transections or sham operations, both cannulae were implanted at the second VAF surgery.

Inhibitory avoidance task

Two weeks after the final surgery the rats were trained on a one-trial step-through inhibitory avoidance task. The apparatus consisted of a trough-shaped alley divided by a sliding door into an illuminated safe compartment and a dark shock compartment ${ }^{19}$. The rat was placed in the safe compartment facing away from the door. As the rat turned around, the door was opened and the rat had free access to the dark side. After the rat entered the dark compartment, the door was closed and a footshock was administered through a Lafayette constant-current stimulator (Model 82400SS, Lafayette).
The shock intensity was calculated as the root mean square of $60 \mathrm{~Hz}$ sinusoidal AC currents. The rat was removed from the alley about $5 \mathrm{~s}$ after receiving the shock and administered the appropriate post-training treatment, and returned to its home cage. On the retention test given $24 \mathrm{~h}$ later, the rat was again placed in the illuminated compartment and the latency to step into the dark compartment was recorded as a measure of retention performance. Rats which did not enter the dark compartment within $600 \mathrm{~s}$ were removed from the alley and assigned a ceiling score of 600 .

\section{Drug administration}

In Expts. I and II, rats received bilateral intra-amygdala injections (vehicle or NE) immediately following training. The animal was gently restrained by the experimenter when receiving injections. The injection was administered through a 30 -gauge injection needle connected to a $10 \mu \mathrm{l}$ Hamilton microsyringe by $0.5 \mathrm{~m}$ PE-20 polyethylene tubing. The injection needle was bent at a length such that, when inserted into the cannula, the needle tip would protrude approximately $1.5 \mathrm{~mm}$ beyond the tip of cannula. Drug solutions were introduced into the PE tubing and the microsyringe, and were delivered into the amygdala bilaterally by a Sage microinjection pump (model 355) at a rate of $1 \mu \mathrm{l} / \mathrm{min}$. (-)-Norepinephrine hydrochloride (Sigma, A-7131) was dissolved into a buffered vehicle, which in $100 \mathrm{ml}$, contained $0.9 \mathrm{~g}$ of $\mathrm{NaCl}, 4.05 \mathrm{ml}$ of $0.2 \mathrm{M}$ $\mathrm{Na}_{2} \mathrm{HPO}_{4}$ and $0.95 \mathrm{ml}$ of $0.2 \mathrm{M} \mathrm{NaH}_{2} \mathrm{PO}_{4} \cdot 2 \mathrm{H}_{2} \mathrm{O}$. All concentrations were calculated as the salt weight. One microliter of solution was injected bilaterally. The injection needle was kept in the cannula for $1 \mathrm{~min}$ after completing the injection to allow for diffusion.

In Expt. III, the rats received s.c. injections of saline or E immediately following training. $\mathrm{E}$ was obtained from Elkins-Sinn. Inc. as a $1 \mathrm{mg} / \mathrm{ml}$ solution (containing $0.1 \%$ sodium bisulfite) and was diluted with saline to appropriate concentrations. The injection volume was $1 \mathrm{ml} / \mathrm{kg}$ b.wt.

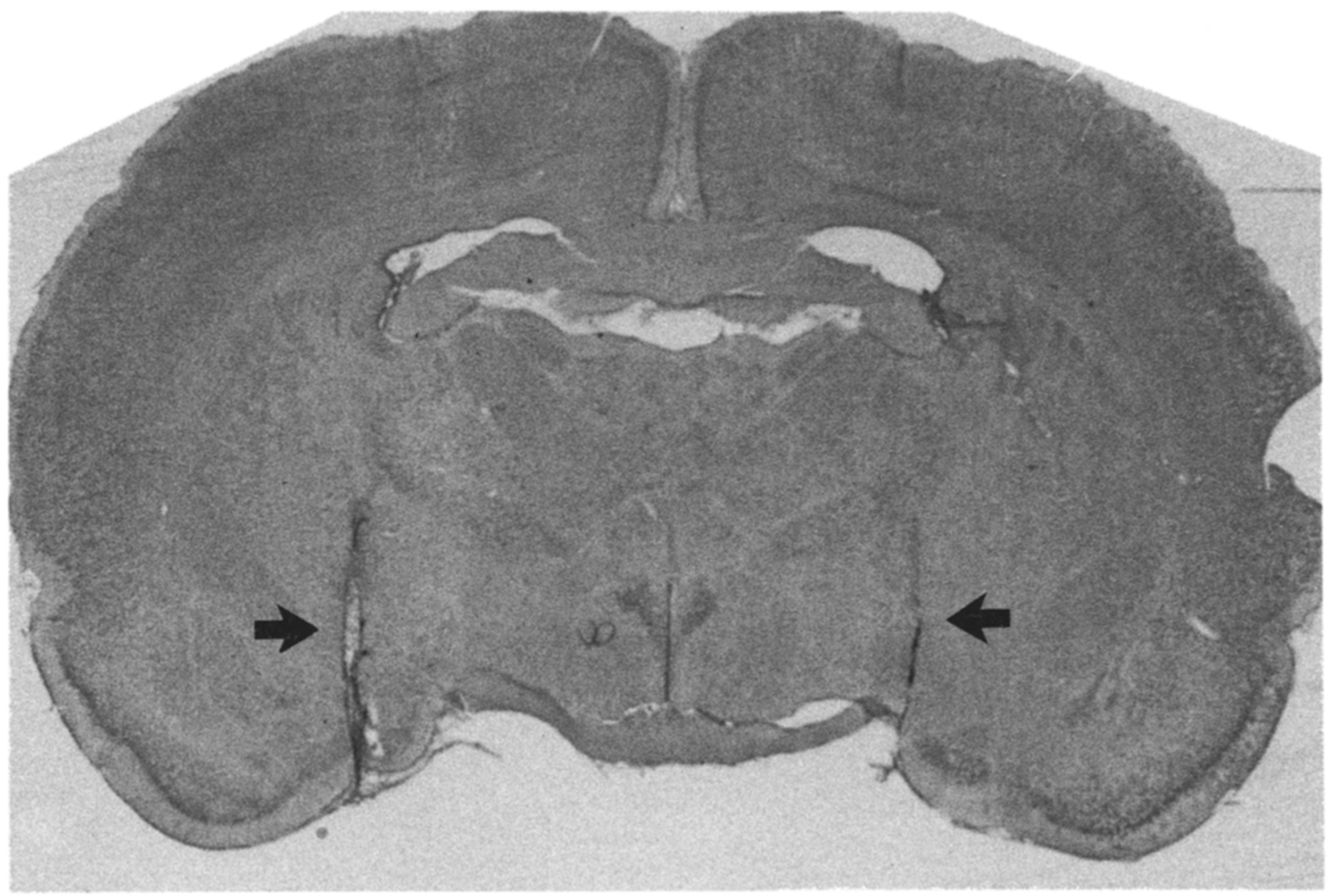

Fig. 2. Representative VAF transections. 

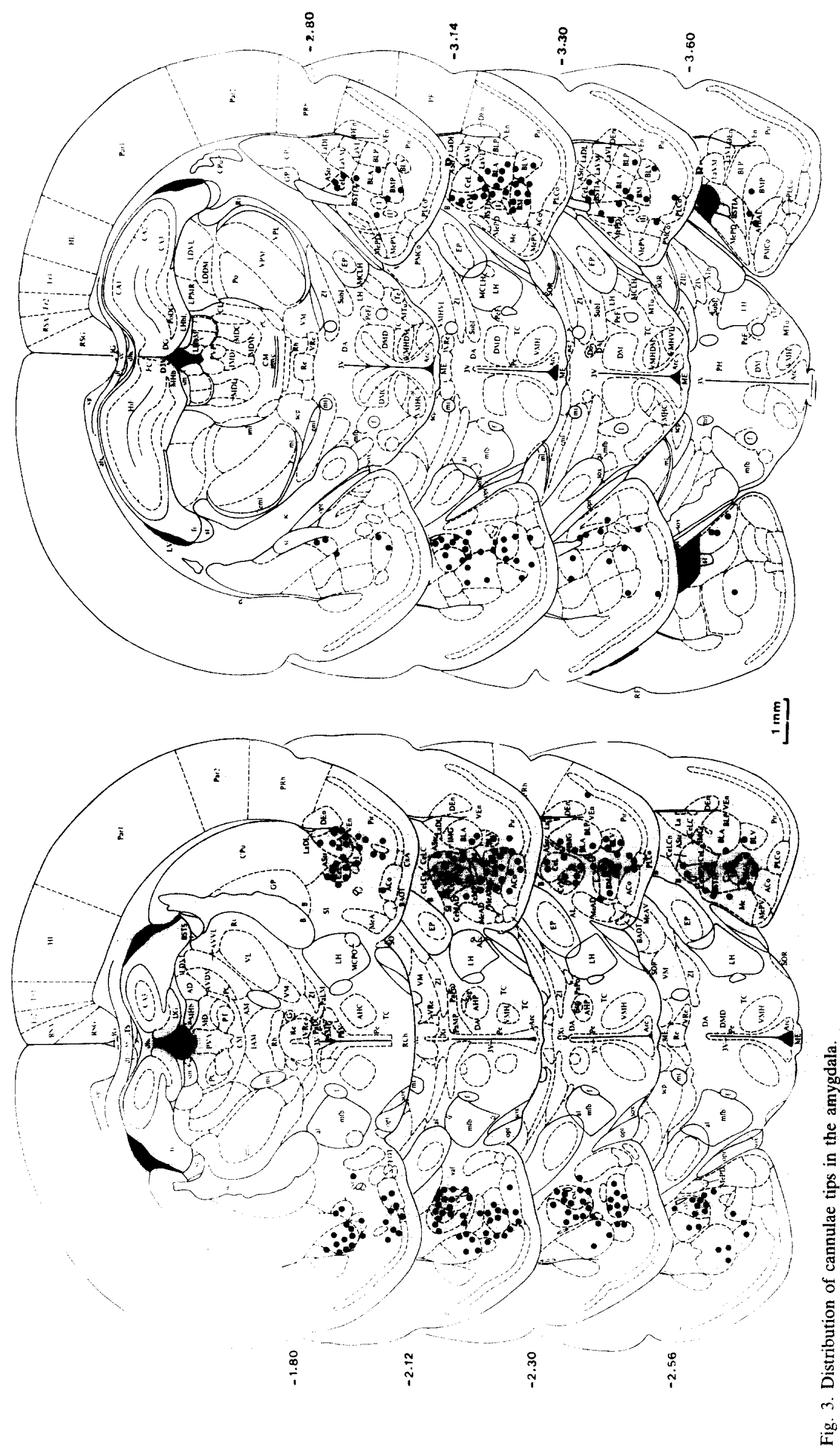


\section{Histology}

The rats were sacrificed with an overdose of sodium pentobarbital and perfused intracardiacally with $0.9 \%$ saline followed by $10 \%$ formalin. The brain was removed and stored in formalin for at least $48 \mathrm{~h}$ and then sectioned into $40-\mu \mathrm{m}$ slices. Slices through the ST lesions, VAF transections and the cannula tract were taken and processed through standard Cresyl violet staining. Animals with cannulae not in the amygdala, or with misplaced lesions or transections were not included in data analyses. The 35 rats discarded for this reason were evenly distributed among various groups. Typical ST lesions, VAF transections and the distribution of amygdala cannula tips within the amygdala are shown in Figs. 1-3.

\section{RESULTS}

\section{Experiment $I$}

The first experiment examined the involvement of the ST and the VAF in mediating the memory facilitation induced by post-training intra-amygdala injections of 0.2 $\mu \mathrm{g}$ NE. In a previous experiment ${ }^{19}$ we found that this dose reliably enhanced retention of the inhibitory avoidance response. Implanted rats with ST lesions (ST-L), ST sham operation (ST-S), VAF transections (VAF-T) or VAF sham operation (VAF-S) were trained on the inhibitory avoidance task with a $0.9 \mathrm{~mA} / 0.9 \mathrm{~s}$ footshock. They received intra-amygdala injections of buffered vehicle (Buf) or $0.2 \mu \mathrm{g} \mathrm{NE}$ immediately after training.

The $24 \mathrm{~h}$ retention performance is shown in Fig. 4 . The distribution of the retention scores was truncated at 600 . Consequently, median and interquartile ranges were used to express the central tendency and the dispersion, respectively, of the data, and non-parametric statistics were used for data anlyses.

In both groups of sham-operated rats (ST-S and VAF-S), post-trial intra-amygdala injections of $0.2 \mu \mathrm{g} \mathrm{NE}$ improved retention: the retention latencies of the ST$\mathrm{S} / \mathrm{NE}$ group were significantly higher than those of the ST-S/Buf group (Mann-Whitney two-tailed $U$-test, $U=$ $29.5, P<0.02$ ), and the latencies of the VAF-S/NE group were significantly higher than those of the VAF-S/Buf group ( $U=20, P<0.01$ ). Lesions of the ST blocked the memory enhancement produced by intra-amygdala injections of $0.2 \mu \mathrm{g} \mathrm{NE}$ : the retention latencies of the ST-L/NE group did not differ significantly from those of the ST-L/Buf group. Further, the retention latencies of the ST-L/NE group were significantly lower than those of the ST-S/NE group ( $U=19, P<0.02)$. Transections of the VAF did not block the memory facilitation caused by $\mathrm{NE}$ : the retention scores of the VAF-T/NE group were significantly higher than those of the VAF-T/Buf group $(U=47, P<0.05)$ and were not significantly different from those of the VAF-S/NE group.

\section{Experiment II}

The findings of Expt. I indicate that the memoryenhancing effect of intra-amygdala injections of $0.2 \mu \mathrm{g}$ $\mathrm{NE}$ is readily blocked by ST lesions but is unaffected by VAF transections. Expt. Il was designed to examine the possibility that the lack of effectiveness of intra-amygdala $\mathrm{NE}$ on retention in ST-L rats might be due to shifts in the dose-response curve. Expt. II also examined the possibility that the lack of NE facilitation in the ST-L rats might be due to a performance-impairing effect of the lesion which was not revealed under the low-footshock training conditions used in Expt. I.

Implanted rats with ST-lesions, VAF-transections or sham operations were trained on the inhibitory avoidance task with a $1.2 \mathrm{~mA} / 1.2 \mathrm{~s}$ footshock. Immediately after
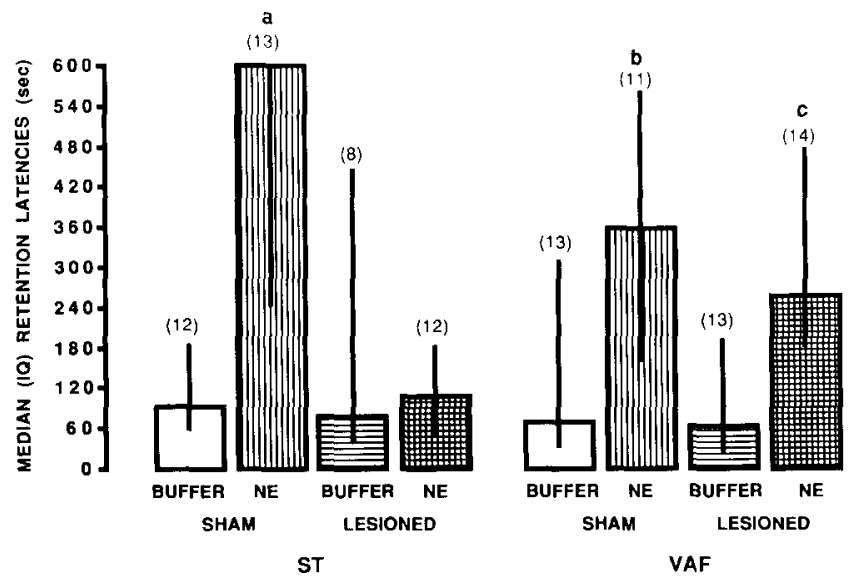

Fig. 4. Retention performance (median \pm interquartile range) of ST-lesioned or VAF-transected rats receiving intra-amygdala injections of $0.2 \mu \mathrm{g} \mathrm{NE}$ immediately after training. a, different from ST Sham/Buf and ST lesioned/NE, $P<0.02 ; \mathrm{b}$, different from VAF Sham/Buf, $P<0.01$; c. different from VAF Transected/Buf, $P<$ 0.05 . Number of subjects in parentheses
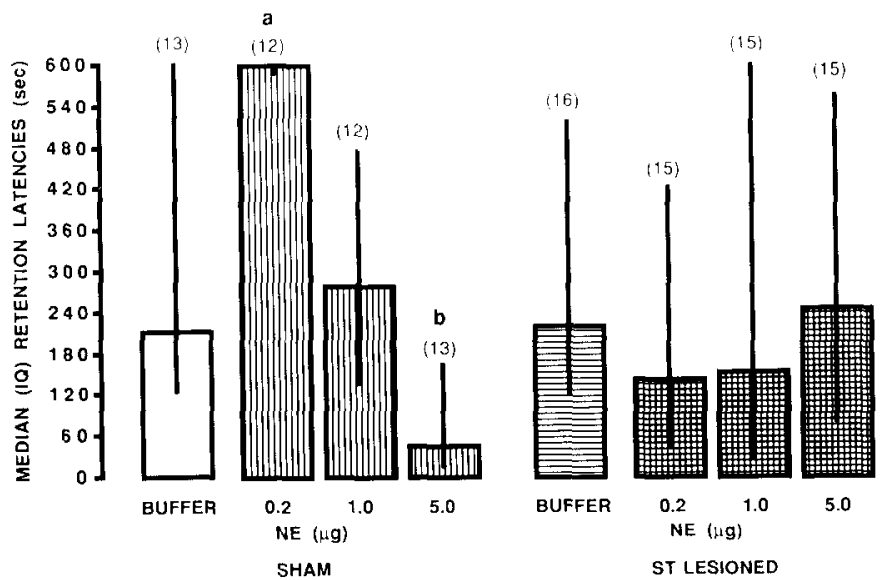

Fig. 5. Retention performance (median \pm interquartile range) of ST-lesioned or sham-operated rats receiving intra-amygdala injections of $\mathrm{NE}$ in the doses indicated. a, different from Sham/Buf, $P$ $<0.01$; different from Lesioned $/ 0.2 \mu \mathrm{g} \mathrm{NE}, P<0.001 ; b$, different from Sham/Buf, $P<0.05$; different from Lesioned $/ 5.0 \mu \mathrm{g} \mathrm{NE}, P<$ 0.05 . Number of subjects in parentheses. 
training, the rats received intra-amygdala injections of Buf or one of 3 doses of NE: $0.2,1.0$ or $5.0 \mu \mathrm{g}$.

The $24 \mathrm{~h}$ retention performance of the ST-operated groups is shown in Fig. 5. In ST-S rats, intra-amygdala injections of NE significantly affected retention performance: a Kruskal-Wallis one-way ANOVA revealed significant differences among various groups $(H=22.60$, $P<0.001)$. Paired comparisons by Mann-Whitney two-tailed $U$-tests indicated that $0.2 \mu \mathrm{g} \mathrm{NE}$ facilitated retention (ST-S/0.2 $\mu \mathrm{g}$ vs ST-S/Buf, $U=30, P<0.01$ ), while $5.0 \mu \mathrm{g} \mathrm{NE}$ impaired retention (ST-S/5.0 $\mu \mathrm{g}$ vs ST-S/Buf, $U=42, P<0.05$ ). The retention performance of the ST-L/Buf rats was not significantly different from that of the ST-S/Buf rats. However, in ST-L rats, post-training intra-amygdala injections of NE did not affect retention performance: none of the $3 \mathrm{ST}-\mathrm{L}$ groups treated with NE had retention scores which were significantly different from those of the ST-L/Buf group. Comparisons between the lesioned and the sham-operated groups receiving the same dose of NE indicated that the retention of the ST-S/ $0.2 \mu \mathrm{g}$ group was significantly better than that of the ST-L $/ 0.2 \mu \mathrm{g}$ group $(U=9.5, P<$ 0.001 ), and the retention of the ST-S/5.0 $\mu$ g group was significantly poorer than that of the ST-L/5.0 $\mu$ g group ( $U$ $=49.5, P<0.05$ ).

The retention performance of the VAF-operated groups is shown in Fig. 6. In VAF sham-operated animals, post-trial intra-amygdala injections of NE produced biphasic effects on retention. A Kruskal-Wallis one-way ANOVA revealed significant differences among various groups $(H=25.98, P<0.001)$. Paired comparisons indicated that $0.2 \mu \mathrm{g} \mathrm{NE}$ facilitated retention (VAF-S $/ 0.2 \mu \mathrm{g}$ vs VAF-S/Buf, $U=22.5, P<0.02$ ), whereas $5.0 \mu \mathrm{g}$ NE impaired retention (VAF-S/5.0 $\mu \mathrm{g}$ vs
VAF-S/Buf, $U=2, P<0.001$ ). Transecting the VAF tended to impair retention: the VAF-T/Buf group had lower retention scores than the VAF-S/Buf group, however, the difference only approached statistical significance $(U=49.5,0.05<P<0.06)$. A Kruskal-Wallis one-way ANOVA showed that the differences among various VAF transected groups were significant $(H=$ 13.99, $P<0.01)$. Paired comparisons indicated that 0.2 $\mu \mathrm{g} N E$ produced significant retention enhancement in the VAF transected rats (VAF-T/0.2 $\mu \mathrm{g}$ vs VAF-T/Buf, $U=$ 43.5, $P<0.005$ ). While retention scores of the VAFT/ $0.2 \mu \mathrm{g}$ group appeared to be lower than those of the VAF-S $/ 0.2 \mu \mathrm{g}$ group, the difference failed to reach statistical significance $(U=50, P=0.10)$. The retention performance of the VAF-T/5.0 $\mu \mathrm{g}$ group did not differ significantly from that of either the VAF-T/Buf group, or the VAF-S/5.0 $\mu \mathrm{g}$ group.

\section{Experiment III}

Previous findings have indicated that noradrenergic innervation of the amygdala is mediated, in part, by the VAF pathway ${ }^{7}$. Thus, if the effects of peripheral $E$ on memory involve NE innervation of the amygdala, transection of the VAF should be expected to attenuate, but not completely block, the effects of E. Expt. III examined this implication.

VAF-T and VAF-S rats were trained on the inhibitory avoidance task with a $0.7 \mathrm{~mA} / 1 \mathrm{~s}$ footshock, They received s.c. injections of saline (Sal) or $0.01,0.1,0.5$ $\mathrm{mg} / \mathrm{kg} \mathrm{E}$ immediately after training. The findings of retention performance tested $24 \mathrm{~h}$ later are shown in Fig. 7. In VAF-S rats, a Kruskal-Wallis one-way ANOVA revealed statistically significant differences among the
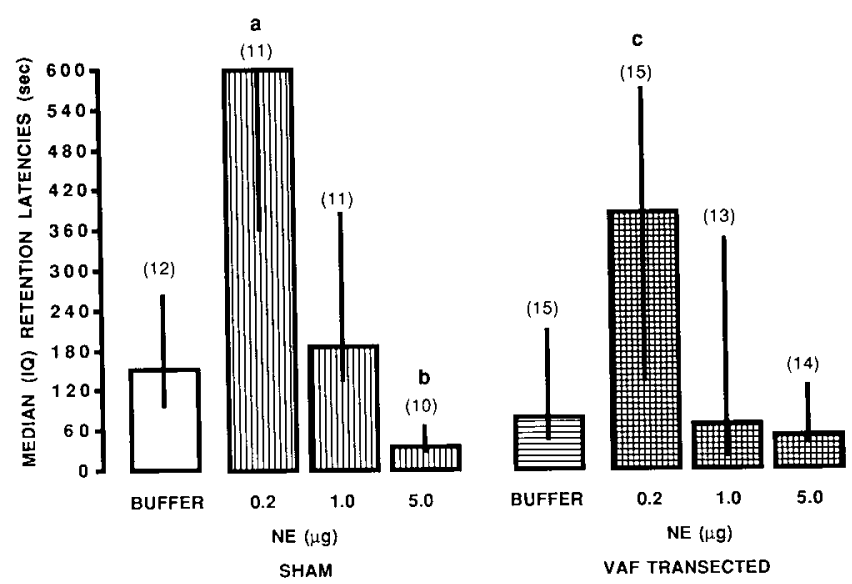

Fig. 6. Retention performance (median \pm interquartile range) of VAF-transected or sham-operated rats receiving intra-amygdala injections of NE at various doses. a, different from Sham/Buf, $P<$ $0.01 ; b$, different from Sham/Buf, $P<0.001$; , different from Transected/Buf, $P<0.05$. Number of subjects in parentheses.
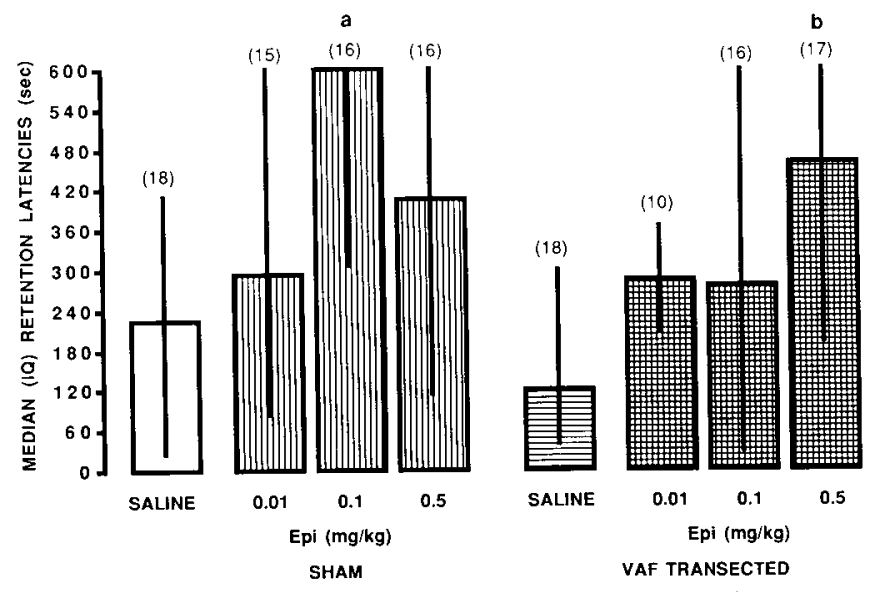

Fig. 7. Retention performance (median \pm interquartile range) of VAF-transected rats receiving subcutaneous injections of $E$. a, different from Sham/Sal, $P<0.01 ; b$, different from Transected/Sal, $P<0.02$. Number of subjects in parentheses. 
groups $(H=8.150, P<0.05)$. Paired comparisons indicated that the retention of the VAF-S/ $0.1 \mathrm{mg}$ group was significantly better than that of the VAF-S/Sal group $(U=63.5, P<0.01)$. The retention scores of the VAF-T rats given Sal tended to be lower than those of the VAF-S rats given Sal, although the difference was not statistically significant. A Kruskal-Wallis one-way ANOVA revealed that the differences among VAF-transected groups only approached statistical significance $(H=6.38$, $0.05<P<0.10$ ). However, the scores of various groups distributed differently, according to a previously set criterion $^{23}$, among low (below 60), medium (60-400) and high (over 400) latencies $\left(\chi^{2}=13.60, P<0.05\right.$ ). This difference was thus pursued further. Paired comparisons indicated that the retention latencies of the VAF-T/0.5 $\mathrm{mg}$ group were significantly greater than those of the VAF-T/Sal group ( $U=88, P<0.05$ ). In contrast, 0.1 $\mathrm{mg} / \mathrm{kg}$ dose of $\mathrm{E}$, which was most effective in enhancing memory of the VAF sham-operated rats, did not significantly influence the retention performance of the VAF-T group.

\section{DISCUSSION}

Three major findings emerged from the present study. First, ST lesions blocked the memory-modulating effects of NE administered intra-amygdally immediately posttraining. Second, transections of the VAF did not block the memory enhancing effect of intra-amygdala injections of NE. Third, transections of the VAF attenuated, but did not block the memory-enhancing effect of peripherally administered $E$ : the effective enhancing dose of $E$ was shifted from $0.1 \mathrm{mg} / \mathrm{kg}$ to $0.5 \mathrm{mg} / \mathrm{kg}$.

In the present study, ST lesions did not affect retention performance of otherwise untreated animals, but blocked both the enhancing and impairing effects of intraamygdala injections of NE at, respectively, low and high doses. These findings, which are consistent with those of previous studies ${ }^{13,14,20-22,27}$, indicate that the blocking of the modulating effect of NE on retention is not due to a general influence of the lesions on retention performance.

Our findings, considered together with those of previous evidence ${ }^{21}$, clearly indicate that an intact ST is essential for the memory-modulating effects of intraamygdala NE, as well as peripheral $\mathrm{E}$. Thus, the findings are consistent with the view that amygdala efferents within the ST mediate the memory-modulating influences initiated by activation of NE receptors within the amygdaloid complex. Alternatively, it might be that the memory modulatory effects of amygdala NE involve efferent influences through other pathways but require integrated ST-mediated input to the amygdala. While the present findings are consistent with both possibilities, our previous findings that the amnestic effect of electrical amygdala stimulation can be blocked by either ST lesions or naloxone, an opiate antagonist, injected into the bed nucleus of the $\mathrm{ST}^{20.24}$ argue that the $\mathrm{ST}$ mediates amygdala outputs involved in modulating memory storage processes.

While the radio frequency used to lesion the ST may have also damaged structures immediately surrounding the ST, such damage does not appear to contribute significantly to the effect of the lesion in blocking the memory modulatory influences. In a previous study we found no correlation between the extent and location of extra-ST damage and the loss of E-induced memory enhancement in ST-lesioned rats ${ }^{21}$. The effect of the ST lesions reported here is also unlikely to be due to a transient effect of the lesions. We previously found that ST lesions made 2-4 weeks prior to training blocked the memory modulatory effect of post-training electrical stimulation of the amygdala without affecting retention performance of otherwise untreated animals ${ }^{20}$

VAF transections, which were produced in sequential unilateral surgeries, failed to block the memory enhancing effect of intra-amygdala NE injections. Such findings are congruent with our previous finding that single-stage bilateral VAF transections failed to attenuate the memory enhancing effect of posttraining electrical stimulation of the amygdala ${ }^{2(}$. In sham-transected (VAF-S) rats, retention was impaired by the high dose of NE $(5.0 \mu \mathrm{g})$. In transected (VAF-T) rats, the effect of the high dose of NE was less clear. The retention performance of the VAF-T/5.0 $\mu \mathrm{g}$ group was not significantly poorer than that of the VAF-T/Buf controls but was not significantly better than that of the VAF-S/5.0 $\mu \mathrm{g}$ group either. And, as was noted above, the retention performance of the latter group was significantly impaired in comparison with that of the VAF-S/Buf controls. Therefore, the question of whether VAF transections attenuate the memory impairing effect of $\mathrm{NE}$ at high doses remains inconclusive and requires further elucidation.

It has been reported that VAF transections, produced by surgical procedures comparable to those used in the present study, result in a $70 \%$ reduction of NE within the amygdala ${ }^{7}$. Thus, on the assumption that the VAF mediates $E$ effects on $\mathrm{NE}$ release within the amygdala, VAF transections should be expected to shift the doseresponse effects of $E$ on retention. Our findings are consistent with this assumption: in the VAF-transected rats, the dose of $E$ required for enhancement of retention was greater than that required for the VAF shamoperated rats. While the present results cannot rule out possible involvement of non-VAF fibers damaged by the transection in the effect, our interpretation of the 
findings are consistent with evidence indicating that partial depletion of amygdala $\mathrm{NE}$ (produced by the neurotoxin DSP-4) attenuates the effects of peripherally administered $E$ on retention ${ }^{18}$, as well as other evidence indicating that the effect of peripherally administered $E$ on memory depends upon the integrity of amygdala functioning ${ }^{19.21}$.

Considered together, the findings of the present experiments are consistent with the view that the VAF mediates, at least in part, peripheral $E$ effects on amygdala NE which influences memory storage through effects involving the ST pathway. This general hypothesis is also consistent with extensive evidence indicating that central noradrenergic neurons are responsive to peripheral visceral challenge, including systemic injections of $\mathrm{E}^{5,12,29,37}$. Peripheral $\mathrm{E}$ might modulate amygdala functioning by activating visceral pathways influencing brainstem NE neurons. Alternatively, E might activate other

\section{REFERENCES}

1 Alheid, G.F, and Heimer, L., New perspectives in basal forebrain organization of special relevance for neuropsychiatric disorders: the striatopallidal, amygdaloid, and corticopetal components of substantia innominata, Neuroscience, 27 (1988) 1-39.

2 Borsini, F. and Rolls, E.T., Role of noradrenaline and serotonin in the basolateral region of the amygdala in food preferences and learned taste aversion in the rat, Physiol. Behav., 33 (1984) $37-43$.

3 Davis, M., Hitchcock, J.M. and Rosen, J.B., Anxiety and amygdala: pharmacological and anatomical analysis of the fear-potentiated startle paradigm. In G.H. Bower (Ed.), The Psychology of Learning and Motivation, Vol. 21, Academic, London, 1987, pp. 263-305.

4 Dietl, H., Temporal relationship between noradrenaline release in the central amygdala and plasma noradrenaline secretion in rats and tree shrews, Neurosci. Lett., 55 (1985) 41-46.

5 Elam, M., Thoren, P. and Svensson, T.H., Locus coeruleus neurons and sympathetic nerves: activation by visceral afferents, Brain Research, 375 (1986) 117-125.

6 Ellis, M.E. and Kesner, R.P., The noradrenergic system of the amygdala and aversive memory processing, Behav. Neurosci., 97 (1983) 399-415.

7 Emson, P.C., Björklund, A., Lindvall, O. and Paxinos, G., Contribution of different afferent pathways to catecholamine and 5-hydroxytryptamine innervation of the amygdala: a neurochemical and histochemical study, Neuroscience, 4 (1979) 1347-1357.

8 Fallon, J.H., Koziell, D.A. and Moore, R.A., Catecholamine innervation of the basal forebrain. II. Amygdala, suprarhinal cortex and entorhinal cortex, J. Comp. Neurol., 180 (1978) 509-532

9 Fallon, J.H., Histochemical characterization of dopaminergic, noradrenergic and serotonergic projections to the amygdala. In Y. Ben-Ari (Ed.), The Amygdala Complex, Elsevier, Amsterdam, 1981, pp. 175-184.

10 Gallagher, M., Kapp, B.S., Pascoe, J.P. and Rapp, P.R., A neuropharmacology of amygdala systems which contribute to learning and memory. In Y. Ben-Ari (Ed.), The Amygdaloid Complex, Elsevier, Amsterdam, 1981, pp. 343-354.

11 Gold, P.E. and van Buskirk, R., Effects of post-trial hormone injections on memory process, Horm. Behav., 7 (1976) 509-517.

12 Holdefer, R.N. and Jensen, R.A., The effects of peripheral
non-NE pathways in the VAF that modulate NE release within the amygdala.

As yet, little is known about brain systems influenced by activation of the ST in the modulation of memory storage. The ST provides reciprocal interconnection between the central nucleus of the amygdala and the bed nucleus of the ST, which project to many brain areas, including the basal forebrain magnocellular cholinergic neurons ${ }^{1}$. Thus, it would be of considerable interest to determine whether endogenous modulatory influences on memory storage is based, at least in part, on interactions of the amygdala with basal forebrain cholinergic systems.

Acknowledgements. We thank Ines Introini-Collison and Nancy Collett for assistance in preparation of this manuscript. This research was supported by Grant NSC-76-0301-H002-02 from the National Science Council of the Republic of China (to K.C.L.) and Office of Naval Research Contract N00014-87-0518 and USPHS Grant MH12526 from the National Institute of Mental Health and the National Institute of Drug Abuse (to J.L.McG).

D-amphetamine, 4-OH amphetamine, and epinephrine on maintained discharge in the locus coeruleus with reference to the modulation of learning and memory by these substances, Brain Research, 417 (1987) 108-117.

13 Introini-Collison, I.B., Arai, Y, and McGaugh, J.L., Stria terminalis lesions attenuate the effects of posttraining atropine and oxotremorine of retention, submitted.

14 Introini-Collison, I.B., Nagahara, A. and McGaugh, J.L., Memory-enhancement with intra-amygdala posttraining naloxone is blocked by concurrent administration of propranolol, Brain Research, 476 (1989) 94-101.

15 Jones, B.E. and Moore, R.Y., Ascending projections of the locus coeruleus in the rat. II. Autoradiographic study, Brain Research, 127 (1977) 23-53.

16 Kapp, B.S., Frysinger, R.C., Gallagher, M. and Bretschneider, A.J., Effects of amygdala and stria terminalis lesions on aversive conditioning in the rabbit, Soc. Neurosci. Abstr., 3 (1973) 236.

17 LeDoux, J.E., Iwata, J. and Reis, D.J., Different projections of the central amygdaloid nucleus mediate autonomic and behavioral correlates of conditioned fear, $J$. Neurosci., 8 (1988) 2517-2529.

18 Liang, K.C. and Chen, L., Intra-amygdala injections of DSP-4 attenuate the memory enhancing effect of peripheral epinephrine, Soc. Neurosci, Abstr., 12 (1986) 702.

19 Liang, K.C., Juler, R.G. and McGaugh, J.L., Modulating effects of posttraining epinephrine on memory: involvement of the amygdala noradrenergic system, Brain Research, 368 (1986) 125-133.

20 Liang, K.C. and McGaugh, J.L., Lesions of the stria terminalis attenuate the amnestic effect of amygdaloid stimulation on avoidance responses, Brain Research, 274 (1983) 309-318.

21 Liang, K.C. and McGaugh, J.L., Lesions of the stria terminalis attenuate the enhancing effect of posttraining epinephrine on retention of an inhibitory avoidance response, Behav. Brain Res., 9 (1983) 49-58.

22 Liang, K.C. and McGaugh, J.L., Effects of adrenal demedullation and stria terminalis lesions on retention of inhibitory avoidance response, Psychobiology, 15 (1987) 154-160.

23 Liang, K.C., McGaugh, J.L., Martinez, Jr., J.L., Jensen, R.A., Vasquez, B.J. and Messing, R.B., Posttraining amygdaloid lesions impair retention of an inhibitory avoidance response, Behav. Brain Res., 4 (1982) 237-249.

24 Liang, K.C., Messing, R.B. and McGaugh, J.L., Naloxone attenuates amnesia caused by amygdaloid stimulation: the 
involvement of a central opioid system, Brain Research, 271 (1983) 41-49.

25 McGaugh, J.L., Hormonal influences on memory, Ann. Rev. Psychol., 27 (1983) 297-323.

26 McGaugh, J.L., Introini-Collison, I. and Nagahara, A., Memory-enhancing effects of posttraining naloxone: involvement of $\beta$-noradrenergic influences in the amygdaloid complex, Brain Research, 446 (1988) 37-49.

27 McGaugh, J.L., Introini-Collison, I., Juler, R.G. and Izquierdo, I., Stria terminalis lesions attenuate the effects of posttraining naloxone and $\beta$-endorphin on retention, Behav. Neurosci., 100 (1986) 839-844.

28 Mishkin, M., Malamut, B. and Bachevalier, J., Memories and habits: two neural systems. In G. Lynch, J.L. McGaugh and N.M. Weinberger (Eds.), Neurobiology of Learning and Memory, Guilford, New York, 1984, pp. 65-77.

29 Morilak, D.A., Fornal, C.A. and Jacobs, B., Effects of physiological manipulations on locus coeruleus neuronal activity in freely moving cats. II. Cardiovascular challenge, Brain Research, 422 (1988) 24-31.

30 Paxinos, G. and Watson, C., The Rat Brain in Stereotaxic Coordinates, Academic, New York, 1986.

31 Peskind, E.R., Raskind, M.A., Wilkinson, C.W., Flatness, D.E. and Halter, J.B., Peripheral sympathectomy and adrenal me- dullectomy do not alter cerebrospinal fluid norepinephrine, Brain Research, 367 (1986) 258-264

32 Ross, J.F. and Grossman, S.P., Transections of stria medullaris or stria terminalis in the rat: effects of aversively controlled behavior, J. Comp. Physiol. Psychol., 70 (1977) 907-915.

33 Sarter, M. and Markowitsch, H.J., Involvement of the amygdala in learning and memory: a critical review, with emphasis on anatomical relationship, Behav. Neurosci., 99 (1985) 342-380.

34 Squire, L., Mechanisms of memory, Science, 232 (1986) 16121619.

35 Squire, L.R. and Cohen, N.J., Human memory and amnesia. In G. Lynch, J.L. McGaugh and N.M. Weinberger (Eds.), Neurobiology of Learning and Memory, Guilford, New York, 1984 , pp. 3-64.

36 Sternberg, D.B., Isaacs, K.R., Gold, P.E. and McGaugh, J.L., Epinephrine facilitation of appetitive learning: attenuation with adrenergic receptor antagonists, Behav. Neural Biol., 44 (1985) 447-453.

37 Svensson, T.H., Peripheral, autonomic regulation of locus coeruleus noradrenergic neurons in brain: putative implications for psychiatry and psychopharmacology, Psychopharmacology, 92 (1987) 1-7.

38 Weil-Malherbe, H., Axelrod, H. and Tomchick, R., Blood-brain-barrier for adrenaline, Science, 129 (1959) 1226-1228. 